\title{
Differentiation of Oligodendroglial Progenitors Derived from Cortical Multipotent Cells Requires Extrinsic Signals Including Activation of gp130/LIF $\beta$ Receptors
}

\author{
Ronen Marmur, ${ }^{2}$ John A. Kessler, ${ }^{1,2}$ Gaofa Zhu, ${ }^{1}$ Solen Gokhan, ${ }^{1,2}$ and Mark F. Mehler ${ }^{1,2,3}$ \\ Departments of ${ }^{1}$ Neurology, ${ }^{2}$ Neuroscience, and ${ }^{3}$ Psychiatry and the Rose F. Kennedy Center for Research in Mental \\ Retardation and Developmental Disabilities, Albert Einstein College of Medicine, Bronx, New York 10461
}

\begin{abstract}
We have previously isolated epidermal growth factor (EGF)responsive multipotent progenitor cells from the early postnatal rodent cerebral cortex independent of generative zones. In this study we have examined the mechanisms regulating the generation of differentiated oligodendrocytes (OLs) from these multipotent cells. Although cultures of primary cortical OL progenitor cells propagated at clonal density spontaneously gave rise to differentiated OLs in defined medium, cultures of multipotent progenitors isolated from identical regions supported the elaboration of OL progenitors but not differentiated OLs. These observations indicate that the terminal maturation of OL progenitors derived from multipotent cells is dependent on signals present within the cellular environment. Application of cytokines such as basic fibroblast growth factor (bFGF), plateletderived growth factor (PDGF), or neurotrophin 3 (NT3) to clonal density cultures of cortical multipotent progenitors increased the proportion of OL progenitors but failed to support the generation of differentiated OLs. By contrast, application of
\end{abstract}

factors that activate gp130/leukemia inhibitory factor $\beta(\operatorname{LIF} \beta)$ heterodimeric receptors, such as ciliary neurotrophic factor (CNTF), activated signal transducers and activators of transcription-3 in these OL progenitor cells and promoted the generation of differentiated OLs. Clonal analysis also demonstrated that CNTF directly targets OL progenitors derived from the multipotent cells. These observations suggest that two distinct progenitor cell pathways contribute to the generation of differentiated OLs during postnatal cortical gliogenesis. Although oligodendroglial maturation of classical OL progenitor cells is driven by cell autonomous mechanisms, our findings demonstrate that the generation of differentiated OLs from cortical multipotent progenitor cells is dependent on environmental cues, including activation of gp130/LIF $\beta$ receptors.

Key words: oligodendrocytes; epidermal growth factor; cortical multipotent progenitor cells; receptor signaling; cytokines; environmental regulation
Oligodendrocytes (OLs), the myelinating cells of the CNS (Del Rio Hortega, 1928; Bunge et al., 1962), develop from neuroepithelial progenitors within periventricular generative zones and subsequently migrate and colonize cortical areas during postnatal gliogenesis (Altman, 1966; Paterson et al., 1973; LeVine and Goldman, 1988a,b; Hardy and Reynolds, 1991). The identification of progressive stages of developing OLs in vivo and in vitro is based on a series of morphological and immunological criteria (Sommer and Schachner, 1981; for review, see Pfeiffer et al., 1993; Barres and Raff, 1994). Under normal conditions in vivo, these

\footnotetext{
Received Feb. 10, 1998; revised Aug. 21, 1998; accepted Sept. 14, 1998.

These studies were supported by an Irma T. Hirschl/Monique-Weill Caulier Career Scientist Award (M.F.M.) and by grants from the Muscular Dystrophy Association (M.F.M.) and the National Institutes of Health (M.F.M and J.A.K.). R.M. was supported (in part) by a National Institutes of Health Medical Scientist Training Program training grant. This work was submitted in partial fulfillment of the requirements for the degree of Doctor of Philosophy, Sue Golding Graduate Division, Albert Einstein College of Medicine (R.M.). We thank the Iowa Hybridoma Bank (5A5 mABs), Dr. Tetsuya Taga of Osaka University (gp130 antibodies), Synergen (CNTF), Dr. Steve Pfeiffer of the University of Connecticut (oligodendroglial marker hybridoma cell lines), Dr. James Darnell of Rockefeller University (STAT-3 antibodies), and Dr. Dave Cosman of Immunex (LIF $\beta$ receptors antibodies) for the supply of experimental reagents; H. Rubin for photography; D. Gephardt for assistance in fluorescence-activated cell sorting analysis; Drs. S. E. Pfeiffer, R. Cohen, R. Gross, and A. Chalazonitis for valuable scientific interactions; and Ms. Antoinette Barnecott and Ms. Michele Briggs for their expert editing of this manuscript.

Correspondence should be addressed to Dr. Mark F. Mehler, Department of Neurology, Albert Einstein College of Medicine, 1410 Pelham Parkway South, Bronx, NY 10461.

Copyright (C) 1998 Society for Neuroscience $\quad 0270-6474 / 98 / 189800-12 \$ 05.00 / 0$
}

cells are solely committed to the oligodendroglial lineage (Groves et al., 1993). The generation of differentiated OLs from OL progenitors is thought to be regulated by cell-intrinsic mechanisms (for review, see Pfeiffer et al., 1993; Barres and Raff, 1994) and by environmental signals (Levison et al., 1993; Ibarrola et al., 1996; for review, see Miller, 1996). Uncommitted progenitor cells that are distinct from "classical" OL progenitor cells may also contribute to postnatal cortical gliogenesis (Levison et al., 1993; Levison and Goldman, 1997). However, the cellular characteristics and anatomical distribution of such putative uncommitted progenitor cells in the cerebral cortex have not been defined.

Recent investigations have suggested that multipotent progenitor cells contribute to cortical development (Reid and Walsh, 1996; Temple and Qian, 1996; Weiss et al., 1996). Epidermal growth factor (EGF)-responsive multipotent progenitor cells present in the subventricular zone (SVZ) play an essential role during perinatal gliogenesis (Lazar and Blum, 1992; Ferrer et al., 1995; Threadgil et al., 1995; Burrows et al., 1997), and these cells generate myelinating OLs in vivo (Hammang et al., 1997). In addition, there is also a population of polysialyated form (PSA)neural CAM (NCAM)-positive, EGF-responsive multipotent progenitor cells present in postnatal cerebral cortex independent of generative zones (Marmur et al., 1998). These observations suggest that at least two separate pools of progenitor cells may contribute to postnatal cortical gliogenesis. One pool consists of OL progenitors that migrate from the SVZ as committed glial 
progenitor cells, whereas the other pool consistsof migratory multipotent cells that retain broad lineage potential in situ.

In this study we have shown that at clonal density, primary cortical OL progenitors undergo spontaneous OL differentiation, whereas OL progenitors derived from cortical multipotent progenitor cells require additional environmental signals, such as cytokines that activate gp130/leukemia inhibitory factor $\beta$ $(\mathrm{LIF} \beta)$ [e.g., ciliary neurotrophic factor $(\mathrm{CNTF})]$, to generate differentiated OLs. In addition, using clonal analysis and signal transducers and activators of transcription-3 (STAT-3) nuclear translocation assays, we have demonstrated that CNTF directly targets OL progenitors derived from the multipotent cells to promote OL differentiation.

\section{MATERIALS AND METHODS}

Animals and growth factor preparations. Sprague Dawley rats were obtained from Taconic Farms. The following growth factor preparations were used: recombinant rat CNTF (a gift from Synergen), recombinant human EGF and recombinant basic fibroblast growth factor (bFGF; Collaborative Biomedical Products), recombinant platelet-derived growth factor (PDGF; Life Technologies, Gaithersburg, MD), and recombinant neurotrophin 3 (NT3; a gift from Genentech, San Francisco, CA).

Microdissection of cortical regions. The forebrains of postnatal day 2 (PN2) rat littermates were surgically separated from the olfactory bulb and the choroid plexus. Coronal tissue sections $(2.5 \pm 0.5 \mathrm{~mm}$ thick $)$ of cerebral hemispheres were obtained with razor blade dissection techniques under fiber optic illumination using a dissecting microscope $(5 \times$; Nikon). For each coronal section, the basic architecture of the cortex, subcortical white matter, periventricular areas, and the striatum was preserved. From each coronal section, cerebral cortical regions were dissected free and placed in $20 \mathrm{~mm}$ HEPES-buffered Earle's balanced salt solution (HEBSS; Gard et al., 1995a,b) in $60 \mathrm{~mm}$ Petri dishes on ice. Clear demarcations between the cerebral cortex and periventricular areas in coronal sections of PN2 brain have allowed the selective isolation of cerebral cortical tissue that is not contaminated by periventricular tissue. Tissue regions were subsequently minced thoroughly with a razor blade into fine tissue fragments.

Mechanical dissociation and immunocytolysis of A2B5-positive progenitors. Dispersed cortical tissue was immersed in HEBSS and digested with trypsin $(0.025 \% ; 15 \mathrm{~min})$ and washed once and digested with DNase as described by Gard et al. (1995a,b). Samples were centrifuged at $150 \times g$ for $10 \mathrm{~min}$ in a bench top centrifuge and resuspended in HEBSS containing DNase and $1 \mathrm{ml}$ of A2B5 monoclonal antibody (mAb; see Immunocytochemistry). The cortical suspensions were then processed for A2B5 immunocytolysis using guinea pig complement at room temperature (45 min). A2B5 immunocytolysis was used to enrich for A2B5negative populations. After immunocytolysis, the complementcontaining medium was changed twice, and the cells were resuspended in HEBSS. Cellular suspensions were then preplated on polystyrene bacteriological grade Petri dishes (Fisher Scientific, Houston, TX) to remove macrophages and fibroblasts by differential adherence. These dissociation techniques are an adaptation of a published protocol [see Gard et al. $(1995 \mathrm{a}, \mathrm{b})$ for a description of the procedure].

Preparation of antibodies for the immunoselection procedure. Ran-2 hybridoma cell lines [mouse $\operatorname{IgG}(\mathrm{mIgG})]$ were obtained from American Type Culture Collection (Rockville, MD), and 5A5 hybridoma cell lines were obtained from the University of Iowa Hybridoma Bank. Unfractionated RAN-2 or 5A5 hybridoma culture medium was collected. Cells were cultured for $7 \mathrm{~d}$ to $100 \%$ confluence and subsequently collected by centrifugation $(600 \times g ; 5 \mathrm{~min})$, and the supernatant was sterilized $(0.22$ $\mu \mathrm{m}$ Millex-GV filter). The final concentration of the antibodies used in the immunoselection procedure was determined for each hybridoma preparation using immunocytochemistry of mixed cortical glial progenitor cell monolayers grown for $7 \mathrm{~d}$ in 5\% fetal calf serum (FCS; Gimmeny Biotechnology) on poly-D-lysine (PDL)-coated coverslips (Cohen et al., 1996). By the use of these monolayers, type 1 astrocytes are RAN-2positive, and early, nonprocess-bearing round OL precursors are PSA-NCAM-immunoreactive (Armstrong et al., 1995).

Sequential purification of PSA-NCAM-positive cells. After preplating, cortical cells were washed once and incubated with $1 \mathrm{ml}$ of Ran-2 antibody in $1 \mathrm{ml}$ of F-12 medium (Life Technologies) for $30 \mathrm{~min}$ in $4^{\circ} \mathrm{C}$.
Cells were washed twice in F-12 medium, incubated with $\mathrm{mIgG}$ conjugated magnetic microbeads diluted (1:5) in PBS supplemented with $0.5 \%$ BSA and $5 \mathrm{~mm}$ EDTA $\left(15 \mathrm{~min} ; 6-10^{\circ} \mathrm{C}\right)$, and processed for magnetic microbead separation using MiniMACS separation columns (Miltenyi Biotec, Sunnyvale, CA) following the manufacturer's instructions. In this step we eliminated $7.1 \pm 3.2 \%$ of the total cortical cells that were Ran-2 immunoreactive at $1 \mathrm{~d}$ in vitro (DIV) (R. Marmur, unpublished observations). The Ran-2-negative cells were then washed once with F-12 medium (Life Technologies) and subsequently incubated with $5 \mathrm{~A} 5$ hybridoma medium $(1 \mathrm{ml})$ in $1 \mathrm{ml}$ of $\mathrm{F}-12$ medium $\left(30 \mathrm{~min} ; 4^{\circ} \mathrm{C}\right)$. Cells were washed twice in F-12 medium, processed for secondary antibody conjugation using mIgM-conjugated magnetic microbeads (see above), and again processed for magnetic separation using MiniMACS separation columns. The 5A5-positive fraction was passaged through a second round of column separation that allowed us to obtain cultures with $>90 \%$ purity for 5A5 immunoreactivity (see Fig. 1).

EGF-generated cortical progenitor cell cultures. Cortical PSA-NCAMpositive cells were obtained as described above and processed for the establishment of EGF-responsive progenitor neurospheres by a modification of methods described previously (Reynolds and Weiss, 1992; Reynolds et al., 1992; Gross et al., 1996). Briefly, neurospheres were grown in serum-free media (SFM) as described previously by Gard et al. (1995a,b): DMEM:F-12 (1:1) containing 0.1\% BSA, $30 \mathrm{~nm}$ selenium, 10 $\mathrm{nm}$ biotin, $30 \mathrm{~nm}$ triiodothyronine, $25 \mu \mathrm{g} / \mathrm{ml}$ transferrin, $20 \mathrm{nM}$ progesterone, $10 \mathrm{~nm}$ hydrocortisone, $1 \mu \mathrm{g} / \mathrm{ml}$ putrescine, $100 \mathrm{units} / \mathrm{ml}$ penicillin, $100 \mu \mathrm{g} / \mathrm{ml}$ streptomycin, and $5 \mu \mathrm{g} / \mathrm{ml}$ insulin. Four days after initial preparation (4DIV), primary neurospheres were washed twice in SFM and plated on PDL-coated coverslips (12 mm; Assistent; 30 neurospheres (NSs) per coverslip) in SFM. To support the generation of moderate density cultures $\left(1.0-1.5 \times 10^{4}\right.$ cells $\left./ \mathrm{cm}^{2}\right)$, we propagated the cells for 2 additional days in EGF $(5 \mathrm{ng} / \mathrm{ml})$. At the start of the experiments, individual coverslips were washed twice with SFM, followed by application of SFM and the appropriate growth factors. The culture medium was changed every fourth day. At the end of each experiment, coverslips were processed for double or triple immunofluorescence microscopic analysis. Total cellular counts for each experimental condition were obtained by examining the entire area of each coverslip from four independent culture wells; the results of each experimental condition were verified a minimum of three times.

Clonal density cultures. For the establishment of clonal density cultures, neurospheres were grown as described above, dissociated, and plated at clonal density $\left(\sim 50-100\right.$ cells $\left./ \mathrm{cm}^{2}\right)$. Cells were propagated in SFM \pm growth factors with media and growth factors replaced every fourth day.

Antibody blocking and conditioned-medium experiments. Moderate density cultures $\left(1 \times 10^{4}\right.$ cells $\left./ \mathrm{cm}^{2}\right)$ of cortical EGF-responsive progenitors were plated on PDL in SFM and propagated for 7 DIV. At days 1, 3 , and 5, the culture medium was replenished, and after $18 \mathrm{hr}$, conditioned medium $(\mathrm{CM})$ was obtained from these culture preparations. After filtration $(0.45 \mu \mathrm{m}), \mathrm{CM}$ was maintained at $4^{\circ} \mathrm{C}$ and used within 24 $\mathrm{hr}$ of processing. For clonal density experiments, CM was used in the following proportions $(\mathrm{v} / \mathrm{v}): 1: 50,1: 20,1: 5,1: 2$, and 1:1. To confirm the cellular effects of LIF $\beta$ R antibodies (LIF $\beta$ R2; 1:200; Immunex, Seattle, WA) on the CNTF-mediated elaboration of differentiated oligodendrocytes (O1-immunoreactive) from cortical multipotent cells propagated at clonal density, LIF $\beta$ R antibodies were initially tested at various concentrations (1:200 optimal), either alone or in concert with CNTF. Cellular preparations were propagated for 9 DIV and subsequently examined for the elaboration of differentiated oligodendrocytes with immunofluorescence microscopy using $\mathrm{O} 1$ antibodies. For analysis of the potential effects of endogenous CNTF-associated ligands on the spontaneous elaboration of the differentiated oligodendrocytes from cortical multipotent progenitors maintained at moderate density, LIF $\beta \mathrm{R}$ and gp130 antibodies (gift of Dr. T. Taga) were applied to these cultures at various concentrations $(1: 20-1: 500)$. We have shown previously that the gp130 antibody effectively blocks the effects of interleukin 6 on STAT-3 activation (phosphorylation; R. Marmur and M. F. Mehler, unpublished observations). Antibody preparations (LIF $\beta$ R, gp130, and LIF $\beta$ R/ gp130) were added at the time of plating, and cellular preparations were examined at 3 DIV for cellular viability [3-(4,5-dimethylthiazol-2-yl)-2,5diphenyl tetrazolium bromide (MTT) assay]; replicate samples were processed for dual immunofluorescence microscopy using antibodies to galactocerebroside (O1) and myelin basic protein.

Primary culture preparations of PN2 OL progenitor cultures. Primary cultures of PN2 OL progenitors were generated as described previously 
by Almazan et al. (1993) and Cohen et al. (1996), using the modifications of McCarthy and deVellis (1980). For immunocytochemical analysis of cellular responsiveness to CNTF (STAT-3 translocation), OL progenitors were processed as described by Cohen et al. (1996). For Western blot analysis of STAT-3 phosphorylation and STAT-3 translocation (see below), the growth factor-containing medium was replaced with SFM, and after an additional $24 \mathrm{hr}$, cultures were further processed for the appropriate experimental analysis.

Immunocytochemistry. For detection of surface antigens, live cells were washed once with PBS/ $0.1 \%$ paraformaldehyde and incubated with monoclonal antibodies [5A5 (mIgM; University of Iowa Hybridoma Bank), A2B5 (mIgM; Eisenbarth et al., 1979), O4 (mIgM; Sommer and Schachner, 1981), and O1/galactocerebroside (mIgM; Sommer and Schachner, 1981)] as hybridoma culture supernatants for $30 \mathrm{~min}$ at $4^{\circ} \mathrm{C}$ (the A2B5, O4, and O1 hybridoma cell lines were a gift of Dr. S. Pfeiffer, University of Connecticut). For immunofluorescence microscopy, the experimental protocols were performed as described previously (Cohen et al., 1996). The cells were further washed twice with PBS and then incubated for $12 \mathrm{hr}$ at $4^{\circ} \mathrm{C}$ using a panel of antibodies: GFAP (mIgG1; 1:400; Sigma, St. Louis, MO), SMI 91 (anti-CNP; mIgG; 1:500; Sternberger Monoclonals Inc.), SMI 99 (anti-MBP; mIgG1; 1:1000; Sternberger Monoclonals Inc.), anti-bromodeoxyuridine (anti-BrdU; mIgG; 1:400; Vector Laboratories, Burlingame, CA), anti- $\beta$ tubulin isotype 3 (mIgG2b; 1:400; Sigma), and anti-STAT-3 [rabbit IgG (rIgG); 1:100; New England Biolabs, Beverly, MA]. The cells were subsequently processed as described previously (Cohen et al., 1996). For triple immunofluorescence analysis, biotinylated secondary antibodies (mIgM; 1:200) were used for biotin-conjugated cascade blue (Molecular Probes, Eugene, OR). Appropriate control samples (omission of primary antibody) were run in parallel with each immunocytochemical preparation. To identify the number of nuclei per microscopic field, we washed cells once in PBS containing Hoechst 33342 for $10 \mathrm{~min}$. At the end of each experiment, coverslips were processed and examined as described previously (Cohen et al., 1996). For immunoperoxidase analysis, cells were processed as described previously (Gross et al., 1996; Mabie et al., 1997). The immunoreactivity and specificity of the A2B5, O4, CNP, and MBP antibodies were verified as described previously (Cohen et al., 1996). Total cellular counts for each experimental condition were obtained by examining the entire area of each coverslip from four independent culture wells; the results of each experimental condition were verified a minimum of three times.

Western blotting for detection of STAT-3 expression in developing oligodendrocytes. Highly enriched developing primary cortical OL progenitors cultures were propagated and processed for Western blot analysis as described previously (Cohen et al., 1996). Primary antibodies included anti-CNPase (mIgG; 1:400; Sigma), SMI 99 (anti-MBP; mIgG1; 1:1000; Sternberger Monoclonals Inc.), and anti-STAT-3 (rIg; a gift of Dr. J. Darnell, Rockefeller University).

Western blot analysis of STAT-3 phosphorylation. Highly enriched cultures of developing OLs (O4-positive/CNP-negative) or EGF-responsive multipotent progenitor cells were incubated with CNTF $(50 \mathrm{ng} / \mathrm{ml})$ for $1-120 \mathrm{~min}$ or with varying doses of CNTF $(0.5-50 \mathrm{ng} / \mathrm{ml})$ for $10 \mathrm{~min}$; RX 187 antibody ( $3 \mu \mathrm{g} / \mathrm{ml}$; gp130-blocking antibody; a gift from Dr. Tetsuya Taga) was added to the culture 15 min before growth factor application in some experimental conditions. The cells were processed for Western blot analysis as described previously (Cohen et al., 1996) using an activation state-specific antibody for STAT-3 (phospho-STAT-3; rabbit IgG; 1:1000; New England Biolabs). The blots were stripped using 62.5 mM Tris buffer, $\mathrm{pH} 6.8$, containing $2 \%$ SDS and $0.7 \% \beta$-mercaptoethanol (stripping buffer) and were reprobed with anti-STAT-3 antibody (1:4000; Upstate Biotechnology, Lake Placid, NY) overnight at $4^{\circ} \mathrm{C}$ as described above. The resulting autoradiograms were compared to standardize the activation or phosphorylation state of STAT-3 relative to the amount of STAT-3 present in each sample. Similar responses were obtained on three separate trials.

Survival assay. The MTT survival assay was performed as previously described by Gard et al. (1995) according to the original procedure of Manthorpe et al. (1986). The EGF-generated multipotent cells were plated at clonal density onto 24 well dishes in SFM with or without individual cytokines as described above. At days 2, 5, 7, and 9, MTT (Sigma) was added to the cultures (final concentration of $0.15 \mathrm{mg} / \mathrm{ml}$ ) and allowed to react for $45 \mathrm{~min}$ at $37^{\circ} \mathrm{C}$. Viable cells converted the MTT to a blue formazan precipitate. The percentage of viable cells per field (four wells, eight random fields, three independent experiments, at $400 \times$ magnification) were counted using a bright-field phase microscope (Olympus).

Proliferation assay. To label cells in the S-phase of the cell cycle, BrdU $(10 \mu \mathrm{M})$ was added to medium-density EGF-responsive cortical cultures on days $1,3,6$, and 8 in vitro. After $24 \mathrm{hr}$, the cells were washed with $0.1 \%$ paraformaldehyde $(1 \mathrm{~min})$, incubated with $\mathrm{O} 4 \mathrm{mAb}$ at $4^{\circ} \mathrm{C}(25 \mathrm{~min})$, washed once with PBS (5 min), and fixed with ice-cold methanol at $-20^{\circ} \mathrm{C}(10 \mathrm{~min})$. The cells were then processed for BrdU staining following the manufacturer's protocol (Vector Laboratories), washed three times (PBS; $5 \mathrm{~min}$ ), and incubated with Ig-subtype-specific secondary antibody for $\mathrm{O} 4$ or $\mathrm{BrdU}(30 \mathrm{~min})$. Cellular preparations were subsequently incubated with Hoechst $33342(10 \mathrm{~min})$ to determine total cell numbers and were thereafter washed in PBS (three times for $10 \mathrm{~min}$ each), mounted, and analyzed using triple immunofluorescence microscopy.

STAT-3 translocation analysis. Coverslips of primary OL progenitor cultures or cultures of EGF-generated progenitors were obtained as described above. Coverslips were washed with $0.2 \%$ paraformaldehyde (90 sec), incubated with A2B5 or O4 mAbs (cortical OL progenitors) at $4^{\circ} \mathrm{C}(25 \mathrm{~min})$, washed once with PBS $(5 \mathrm{~min})$, and fixed with ice-cold methanol at $-20^{\circ} \mathrm{C}(10 \mathrm{~min})$. The cells were then processed for immunoperoxidase staining with anti-STAT-3 antibodies (rabbit IgG; 1:100; New England Biolabs) as described above. After completion of the immunoperoxidase procedure, cells were incubated with Ig-subtypespecific secondary antibody for $\mathrm{O} 4(30 \mathrm{~min})$ and subsequently incubated with Hoechst $33342(10 \mathrm{~min})$ to determine total cell numbers. Cells were thereafter washed in PBS (three times for $10 \mathrm{~min}$ each), mounted, and analyzed using combined immunofluorescence and light microscopy.

\section{RESULTS}

\section{Primary cortical OL progenitor cells but not OL progenitors derived from cortical multipotent progenitors give rise to differentiated oligodendrocytes by cell autonomous mechanisms}

We have shown previously that multipotent progenitors and OL progenitors are present in the early postnatal cerebral cortex outside of traditional periventricular generative zones and exhibit distinct cellular properties (Marmur et al., 1999). Although OL progenitors isolated from a variety of CNS regions are capable of generating differentiated OLs by cell autonomous mechanisms, the mechanisms that regulate progressive OL maturation from multipotent progenitors have not been defined. To examine this issue, we established clonal density cultures of EGF-responsive multipotent progenitors (see Materials and Methods) and determined the profiles of generation of differentiated OLs. Multipotent progenitor cells gave rise to O4-immunoreactive preoligodendrocytes that failed to further differentiate spontaneously (Fig. 1). Consistent with previous reports, primary cortical OL progenitors spontaneously gave rise to differentiated OLs (O1immunoreactive; Fig. 2) without the need for exogenous cues. These observations suggest that OL progenitors derived from cortical multipotent progenitors require additional environmental signals for OL differentiation.

\section{Generation of differentiated OLs from OL progenitors derived from cortical multipotent progenitors is dependent on environmental signals including CNTF}

Recent studies have suggested that the elaboration of the OL lineage may require the interplay of cell-intrinsic and environmental cues and that these developmental mechanisms may be region-specific (Levison et al., 1993; Barres and Raff, 1994; Miller, 1996). Although it has been shown previously that CNTF enhances the generation of differentiated OLs (Mayer et al., 1994; Ibarrola et al., 1996), recent studies have questioned these observations (Barres et al., 1996). Because our clonal density cultures supported the generation of OL progenitors but not differentiated OLs (Fig. $1 A, B$ ), we have used this model system to test the 
A

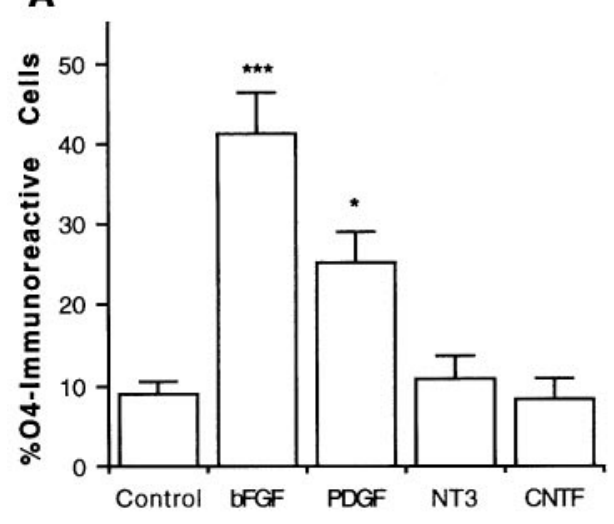

B

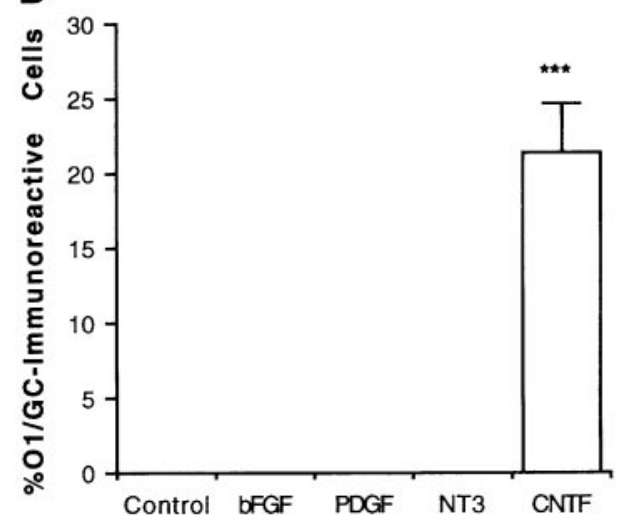

\section{C1}

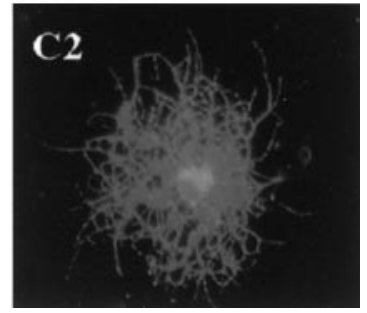

Figure 1. Generation of differentiated oligodendrocytes in clonal density cultures after cytokine application. $A$, Clonal density cultures of cells derived from postnatal cortical progenitor neurospheres were propagated in the absence or presence of $P D G F(5 \mathrm{ng} / \mathrm{ml}), N T 3(25 \mathrm{ng} / \mathrm{ml}), b F G F(2.5 \mathrm{ng} / \mathrm{ml})$, or $C N T F(10 \mathrm{ng} / \mathrm{ml})$. After $9 \mathrm{~d}$, the percentage of $O 4$-positive cells was determined using double immunofluorescence microscopy. $B$, Replicate wells were propagated with growth factors for $9 \mathrm{~d}$ and the percentage of $O 1$-positive cells was quantified. $C$, Photomicrographs of $O 1$-positive cells observed in control $(C 1)$ and $C N T F(C 2)$ treatment conditions are shown. Each bar represents the mean \pm SEM of 64 independent wells $\left(\mathrm{cm}^{2}\right)$ in four separate experiments. Statistical significance was determined using ANOVA with Bonferroni post hoc analysis: * $p<0.05$; *** $p<0.001$. GC, Galactocerebroside.

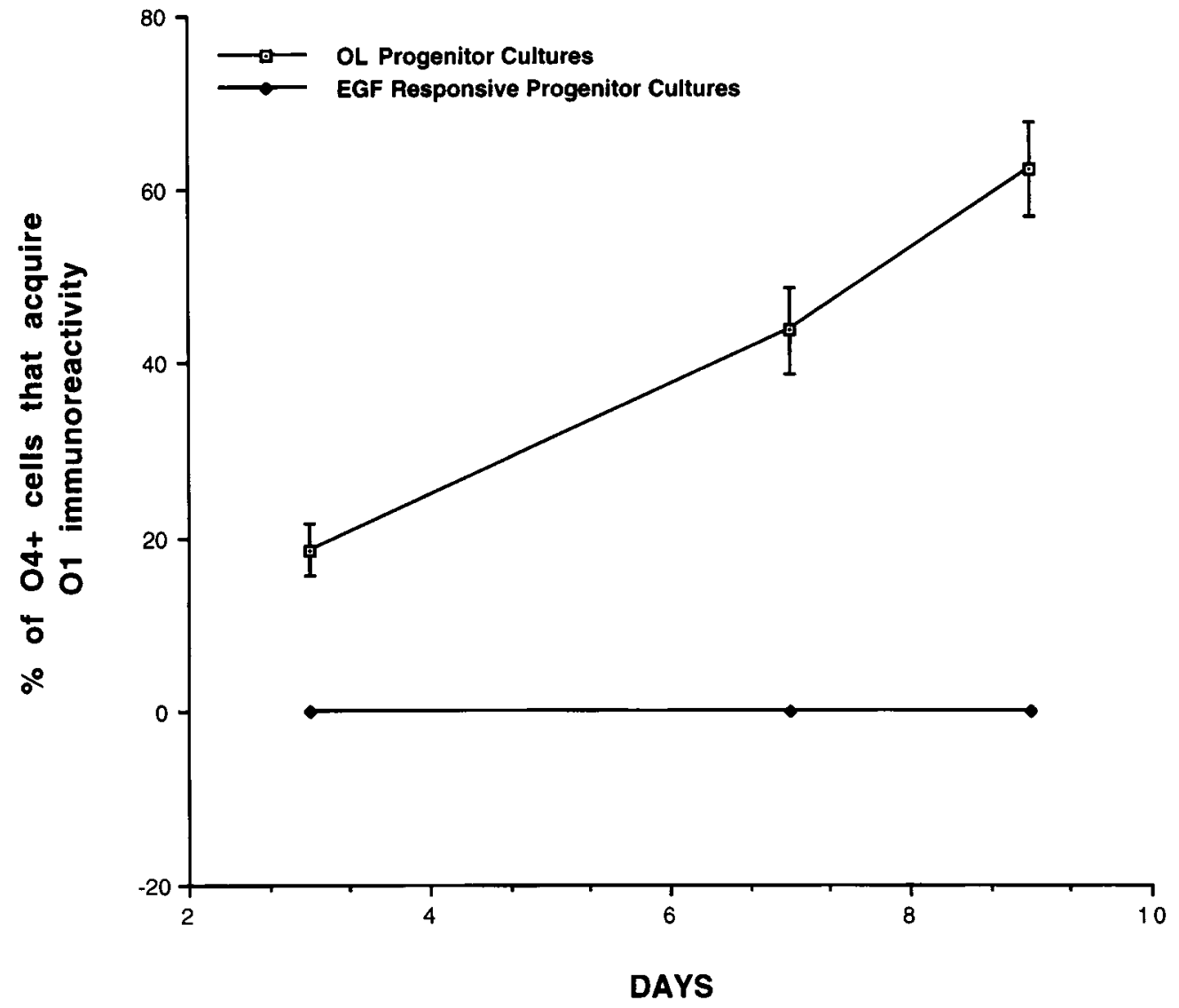

Figure 2. Generation of differentiated OLs from cortical OL progenitor cells but not from cortical multipotent progenitors. Clonal density cultures of OL progenitors and multipotent progenitors were established in basal media (see Materials and Methods), and O1-immunoreactive cells were quantified after 3, 7, and $9 \mathrm{~d}$. Each bar represents the mean \pm SEM of four independent fields $\left(\mathrm{cm}^{2}\right)$ in six separate experiments. hypothesis that CNTF enhances the generation of OLs. After $9 \mathrm{~d}$ in culture in SFM, a significant percentage $(9.1 \pm 1.3 \%)$ of the total cells was O4-positive and O1-negative, suggesting that basal culture conditions support the generation and survival of preoligodendrocytes (Fig. 1 $A$ ) but not differentiated OLs (Fig. 1B). Application of PDGF or bFGF but not NT3 significantly increased the proportion of O4-immunoreactive cells (Fig. $1 A$;
Table 1; Marmur et al., 1999) but failed to support the generation of differentiated OLs (Fig. 1B). By contrast, application of CNTF promoted the dose-dependent generation of differentiated O1positive OLs $[0.1 \mathrm{ng} / \mathrm{ml}, 2.6 \pm 0.9 \% ; 1.0 \mathrm{ng} / \mathrm{ml}, 9.3 \pm 1.7 \%$; and $10 \mathrm{ng} / \mathrm{ml}, 21.6 \pm 3.4 \%$ O1-positive/total cells; Fig. $1 B, C]$ but did not significantly increase the cellular proportions of O4-positive OL progenitors, astrocytes, or neurons (Fig. 3). Analysis of cel- 


\begin{tabular}{|c|c|c|c|}
\hline \multicolumn{4}{|c|}{$\begin{array}{l}\text { Table 1. Proliferation and survive } \\
\text { clonal density cultures } \\
\qquad \% \text { Total cells }\end{array}$} \\
\hline & Control & CNTF & PDGF \\
\hline \multicolumn{4}{|l|}{ BrdU+ } \\
\hline $2 \mathrm{~d}$ & $10.0 \pm 2.9$ & $9.3 \pm 1.8$ & $22.4 \pm 4.7$ \\
\hline $5 \mathrm{~d}$ & $5.9 \pm 1.4$ & $4.7 \pm 1.8$ & $17.7 \pm 3.6$ \\
\hline $7 \mathrm{~d}$ & $3.2 \pm 1.6$ & $2.9 \pm 1.2$ & $14.3 \pm 3.1$ \\
\hline $9 \mathrm{~d}$ & $1.4 \pm 0.9$ & $1.0 \pm 0.6$ & $8.7 \pm 2.1$ \\
\hline \multicolumn{4}{|c|}{ MTT+ } \\
\hline $2 \mathrm{~d}$ & $96.2 \pm 2.4$ & $97.3 \pm 3.7$ & $95.3 \pm 3.1$ \\
\hline $5 \mathrm{~d}$ & $94.1 \pm 3.1$ & $95.3 \pm 2.7$ & $94.9 \pm 1.9$ \\
\hline $7 \mathrm{~d}$ & $92.4 \pm 1.9$ & $93.1 \pm 2.1$ & $92.8 \pm 2.2$ \\
\hline $9 \mathrm{~d}$ & $91.2 \pm 1.1$ & $92.1 \pm 1.5$ & $92.0 \pm 1.6$ \\
\hline
\end{tabular}

See Materials and Methods for detailed descriptions of clonal density culture paradigms and BrdU and MTT analyses. CNTF (20 ng/ml); PDGF (5 ng/ml).

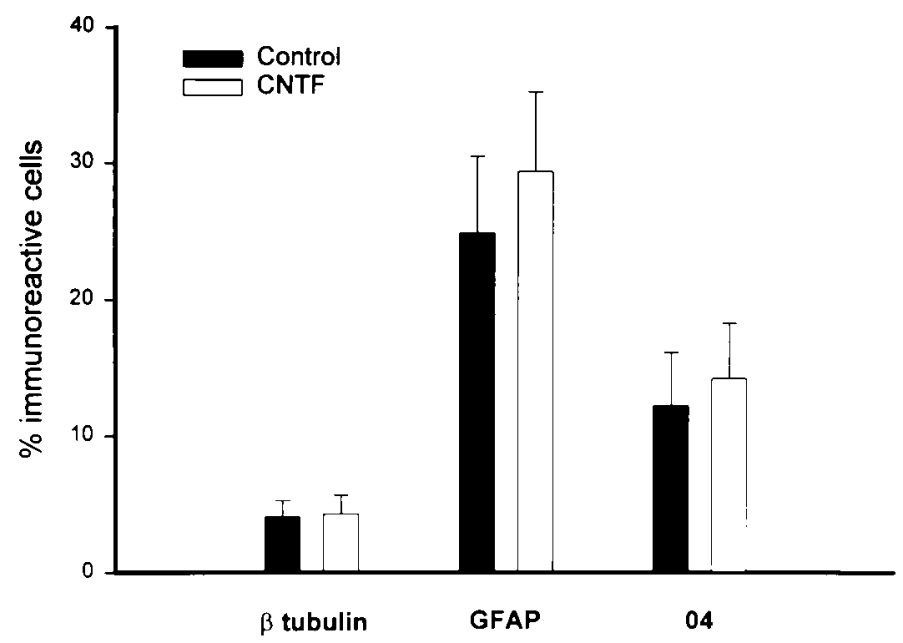

Figure 3. Generation of neurons, astrocytes, and oligodendrocytes from multipotent progenitor cells with and without CNTF. Clonal density cultures of cells derived from postnatal cortical progenitor neurospheres were propagated in the absence or presence of $C N T F(10 \mathrm{ng} / \mathrm{ml})$. After $9 \mathrm{~d}$, the percentage of $\beta$ tubulin-, GFAP-, and O4-positive cells was determined using triple immunofluorescence microscopy. Each bar represents the mean \pm SEM of 20 independent fields $\left(\mathrm{cm}^{2}\right)$ in three separate experiments.

lular viability (MTT assay) demonstrated that these culture conditions supported the robust cumulative survival $(>90 \%)$ of progenitor species for 9 DIV (Table 1). Furthermore, BrdU analysis (see Materials and Methods) has shown that control and CNTF conditions display similar degrees of progenitor cell proliferation (Table 1). Double immunofluorescence analysis (O4/BrdU) confirmed that CNTF is not acting as a mitogen in these cultures (data not shown). In addition, analysis of mean clonal size over time demonstrates similar profiles between control and CNTF treatment conditions (mean clone size: cell number, for control, day 2, $2.2 \pm 1.3$; day 4, $3.8 \pm 1.7$; and day 9, $5.1 \pm 1.7$; for CNTF, day 2, $1.8 \pm 1.1$; day $4,3.1 \pm 1.6$; and day $9,4.8 \pm 1.9$ ). Thus, alterations in survival and proliferation could not explain the absence of differentiated OLs in the cortical clonal cultures. We further examined the clonal composition of the cells derived from cortical multipotent progenitors in the presence or absence of CNTF (Fig. 3). Our results demonstrate that multipotent progenitors give rise to a significant proportion of oligodendroglial, astroglial, and neuronal lineage species and that CNTF does not alter these lineage profiles (Fig. 3). Thus, CNTF does not act by promoting the elaboration of the OL lineage at the expense of other lineages (instructive mechanism). In addition, the absence of preferential survival or proliferation in the CNTF treatment condition and the absence of differentiated OLs in the control condition strongly suggest that CNTF acts directly on OL progenitors to promote their cellular differentiation. The fact that CNTF acts directly on OL progenitors was further supported by analysis of STAT-3 translocation in OL progenitor species evaluated by immunocytochemical analysis (see below and Fig. 7).

\section{Generation of differentiated OLs from cortical EGF- responsive multipotent progenitors can also be promoted by other environmental cues that act in concert with CNTF}

To define further conditions that support the generation of differentiated OLs, we established clonal, moderate, and high density cultures of cortical EGF-generated progenitor cells, propagated them for $8 \mathrm{~d}$ in SFM, and quantified the number of OL progenitors (O4-immunoreactive), immature OLs [O1immunoreactive $(\mathrm{O} 1+)]$, and mature OLs [MBP-immunoreactive $(\mathrm{MBP}+)$ ] generated in each experimental condition. Unlike clonal density cultures, moderate and high density cultures of progenitor cells generated significant complements of differentiated OLs: clonal density, no cells were $\mathrm{O} 1+$ or $\mathrm{MBP}+$; moderate density, $12.2 \pm 2.9 \%$ of the total cells were $\mathrm{O} 1+$, and $3.8 \pm 1.5 \%$ were $\mathrm{MBP}+$; high density, $16.7 \pm 3.4 \%$ of the total cells were $\mathrm{O} 1+$, and $5.7 \pm 2.0 \%$ were $\mathrm{MBP}+$. These observations suggest that factor(s) expressed within these cultures promote the generation of differentiated OLs. Thus, OL maturation can also be supported by signals present within the progenitor cell culture system.

We next examined whether CNTF potentiates the effects of other environmental (density-dependent) signals that support the generation of differentiated OLs from cortical multipotent cells. Accordingly, progenitor cells were cultured at moderate density for $3 \mathrm{~d}$ (Fig. 4) with varying concentrations of CNTF, and the number of differentiated OLs was quantified. Application of CNTF caused a significant dose-dependent enhancement of the number of advanced differentiated OLs $(0.1 \mathrm{ng} / \mathrm{ml}, 4.7 \pm 1.1 \%$ MBP-positive/total cells; $1.0 \mathrm{ng} / \mathrm{ml}, 8.9 \pm 1.7 \% \mathrm{MBP}-$ positive/ total cells; and $10 \mathrm{ng} / \mathrm{ml}, 12.7 \pm 2.3 \% \mathrm{MBP}$-positive/total cells) without altering the proportion of OL progenitors (O4-positive; Fig. $4 A, B)$. Furthermore, CNTF did not alter either proliferation (BrdU labeling) or survival (MTT assay) of progenitor cells (data not shown). Thus activation of gp130/LIF $\beta$ receptors promotes the differentiation of OL progenitors and acts in concert with additional environmental cues.

To determine further whether signals other than those mediated by CNTF-related cytokines were responsible for the elaboration of differentiated OLs from cortical EGF-generated progenitors at higher densities, we performed several additional experiments using LIF $\beta$ R- and gp130-blocking antibodies and conditioned media obtained from higher density cultures. By the use of clonal density culture paradigms identical to those outlined above (see Fig. $1 B$ ), LIF $\beta$ R-blocking antibodies significantly inhibited the CNTF-mediated elaborations of differentiated OLs from cortical EGF-responsive progenitors (Fig. 5B; also see Materials and Methods). By contrast, gp130-blocking antibodies (see Materials and Methods) had no effect on the CNTF-mediated promotion of the generation of differentiated OLs within this same experimental paradigm (data not shown). When moderate density cultures of cortical EGF-responsive multipotent progen- 

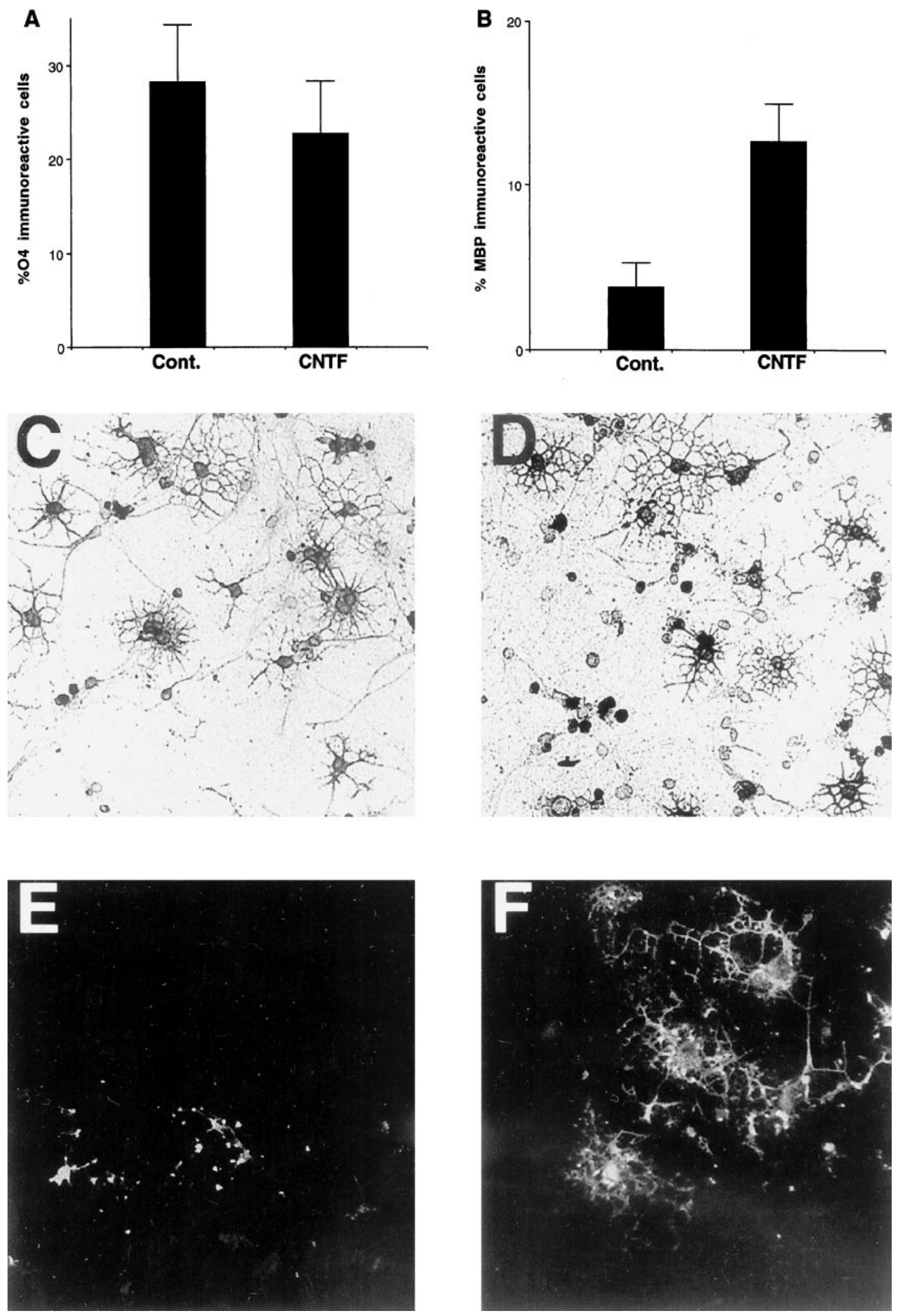

Figure 4. Generation of differentiated oligodendrocytes after $3 \mathrm{~d}$ in moderate density cultures after gp130-associated cytokine applications. $A, B$, Neural precursors $\left(1 \times 10^{4}\right.$ cells $\left./ \mathrm{cm}^{2}\right)$ derived from postnatal cortical progenitor neurospheres were propagated in SFM with and without factors, and after $3 \mathrm{~d}$ the percentage and the number of $O 4$ - and $M B P$-positive cells were determined using double immunofluorescence microscopy. $C-F$, Replicate wells were processed for immunofluorescence analysis using $O 4(C, D)$ and anti-MBP $(E, F) \mathrm{mAbs}$. Photomicrographs of cells in the control condition $(C, E)$ and after application of $C N T F(D, F)$, demonstrating the enhanced number of $M B P$-positive cells in the CNTF treatment condition, are shown. In $A$ and $B$, each bar represents the mean \pm SEM of four independent observations in three separate experiments, and statistical significance was determined using ANOVA with Bonferroni post hoc analysis. In $B$, the $C N T F$ treatment condition displayed a highly significant potentiation of $M B P$-immunoreactive cells $(p<0.001)$. 

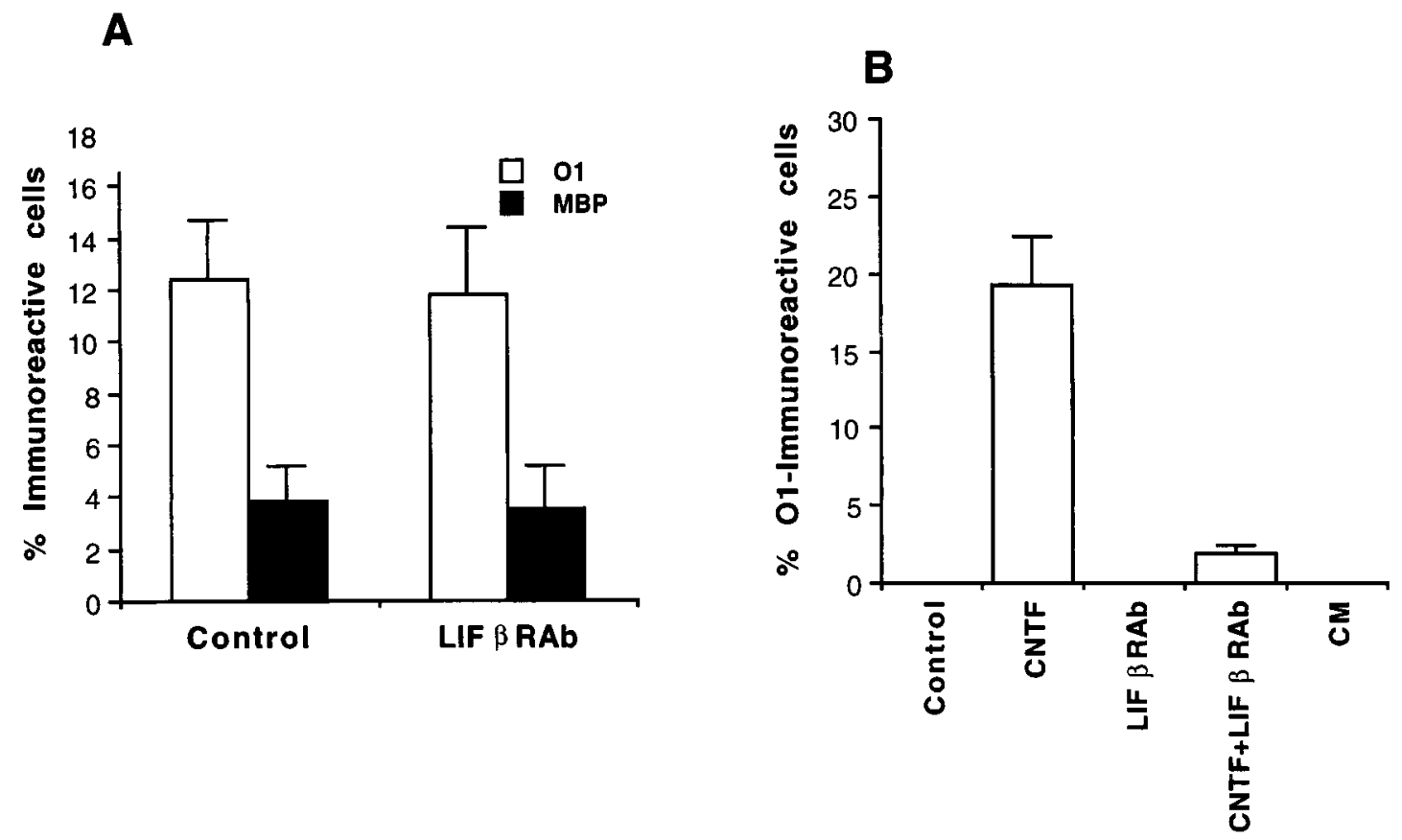

Figure 5. Examination of the properties of environmental signals that potentiate the elaboration of differentiated oligodendrocytes from moderate density cultures of cortical EGF-responsive progenitors. $A$, Cortical EGF-responsive progenitors were plated at moderate density in SFM without or with the presence of LIF $\beta$ R antibodies $(\operatorname{LIF} \beta R A b)$ and propagated for 3 DIV. At that time, cellular preparations were fixed and processed for double immunofluorescence microscopy using $O 1$ and $M B P$ antibodies, and the percentage of differentiated $(O 1$ and $M B P)$ oligodendrocytes in each experimental condition was quantified. $B$, Cortical EGF-responsive progenitors were plated at clonal density in SFM without or with the individual or coapplication of $C N T F$ ligand and $L I F \beta R$ antibody or $C M$ from moderate density cultures of cortical EGF-responsive progenitors and were propagated for 9 DIV in paradigms identical to those described in Figure 1. After 9 d, cellular preparations were fixed and processed for immunofluorescence microscopy using $\mathrm{Ol}$ antibodies, and the percentage of differentiated oligodendrocytes in each experimental condition was quantified.

itors were propagated for 3 DIV in SFM without and with the application of LIF $\beta \mathrm{R}$ antibodies at several reagent concentrations (see Materials and Methods), there were no significant differences between control and experimental conditions in the percentage of differentiated $(\mathrm{O} 1+$ and $\mathrm{MBP}+) \mathrm{OLs}$ generated (Fig. 5A). Furthermore, individual application of gp130 antibodies or coapplication of gp130 and LIF $\beta$ receptor antibodies did not change the basal profiles of elaboration of differentiated OLs from cortical EGF-responsive progenitors (data not shown). These cumulative observations suggest that endogenous signals other than those mediated by gp130 and LIF $\beta$ receptors are responsible for the generation of differentiated OLs from cortical EGF-responsive progenitors observed in higher density culture preparations. To confirm these experimental findings further, we applied CM from moderate density cultures to clonal density cultures of cortical EGF-responsive progenitors to determine whether endogenous soluble signals present in moderate density cultures could reproduce the CNTF-mediated generation of differentiated OLs present in clonal density cultures. CM harvested from different progenitor culture stages and applied at various concentrations (see Materials and Methods) also failed to promote the generation of differentiated OLs from cortical EGFresponsive progenitors propagated at clonal density (Fig. 5B).

\section{A subpopulation of EGF-responsive multipotent progenitors derived from the postnatal cerebral cortex exhibits STAT-3 phosphorylation and nuclear translocation after activation of gp130/LIF $\beta$ heterodimeric receptors}

CNTF is expressed in cortical regions and in the corpus callosum during postnatal cortical gliogenesis, and there is strong genetic evidence that additional CNTF- or LIF-like ligands contribute to normal CNS development and gliogenesis (Stockli et al., 1991; Schobitz et al., 1992, 1993; DeChiara et al., 1995; Gard et al., 1995a,b; Ware et al., 1995). To define further the cellular actions of cytokines that activate gp130/LIF $\beta$ heterodimeric receptors in cortical multipotent cells, EGF-responsive multipotent progenitors were treated with CNTF or LIF and were lysed and processed for Western blot analysis after 5, 30, and $120 \mathrm{~min}$ to detect the presence of phosphorylated STAT-3. CNTF or LIF induced rapid but transient phosphorylation of STAT-3 in doses ranging from 0.5 to $50 \mathrm{ng} / \mathrm{ml}$ (Fig. 6). Furthermore, coapplication of antibodies that specifically block gp130/gp130 homodimeric signaling did not attenuate STAT-3 phosphorylation, suggesting that activation of this latent cytoplasmic transcriptional activator was specifically induced by gp130/LIF $\beta$ heterodimeric receptor subunits (Fig. 6).

We next sought to quantify the proportion of progenitors within the multipotent cellular cultures that respond to CNTF. Previous studies have shown that activation of gp130/LIF $\beta$ heterodimeric receptors that mediate CNTF developmental signals results in nuclear translocation of the latent transcriptional regulator STAT-3 (Zhong et al., 1994a,b). We have used STAT-3 nuclear translocation assays (see Materials and Methods) to determine the proportion of CNTF-responsive progenitor cells within the multipotent progenitor cell cultures. Only a proportion of cells within the multipotent progenitor cultures was responsive to a saturating concentration of CNTF (17.5 $\pm 3.8 \%$; Fig. 7). We therefore sought to identify the specific progenitor species that are responsive to CNTF. Double immunocytochemical analysis demonstrated that virtually all O4-immunoreactive cells $(96.2 \pm$ $0.5 \%$ ) exhibited STAT-3 nuclear translocation. A small subpopu- 


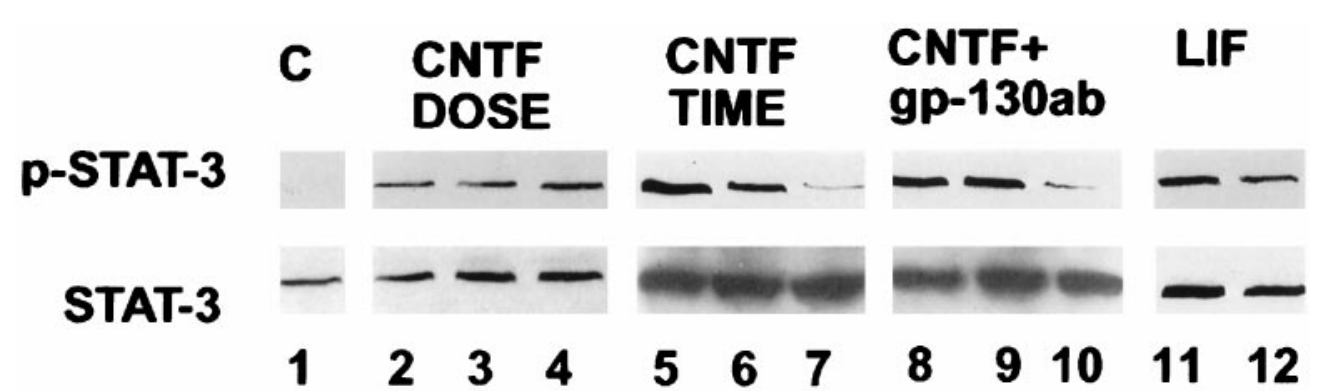

Figure 6. Phosphorylation of STAT-3 in neural precursors derived from cortical multipotent cells after application of gp130-associated cytokines. Western blot analysis demonstrating the levels of expression of phosphorylated STAT-3 ( $p-S T A T-3$; top) and total STAT-3 protein (bottom) before and after activation of gp130/LIF $\beta$ heterodimeric receptors. Lane 1, Control (C); lanes 2-4, CNTF dose curve with $0.5 \mathrm{ng} / \mathrm{ml}$ (lane 2), $5 \mathrm{ng} / \mathrm{ml}$ (lane 3), and $50 \mathrm{ng} / \mathrm{ml}$ (lane 4) for $10 \mathrm{~min}$; lanes 5-10, factor stimulation for 5, 30, and $120 \mathrm{~min}$ with CNTF (50 ng/ml; lanes 5-7) or with CNTF (50 ng/ml) and gp130-blocking antibodies (gp-130ab; lanes 8-10); and lanes 11, 12, LIF $\beta$ (LIF; $50 \mathrm{ng} / \mathrm{ml}$ ) after 5 min (lane 11) and 30 min (lane 12).
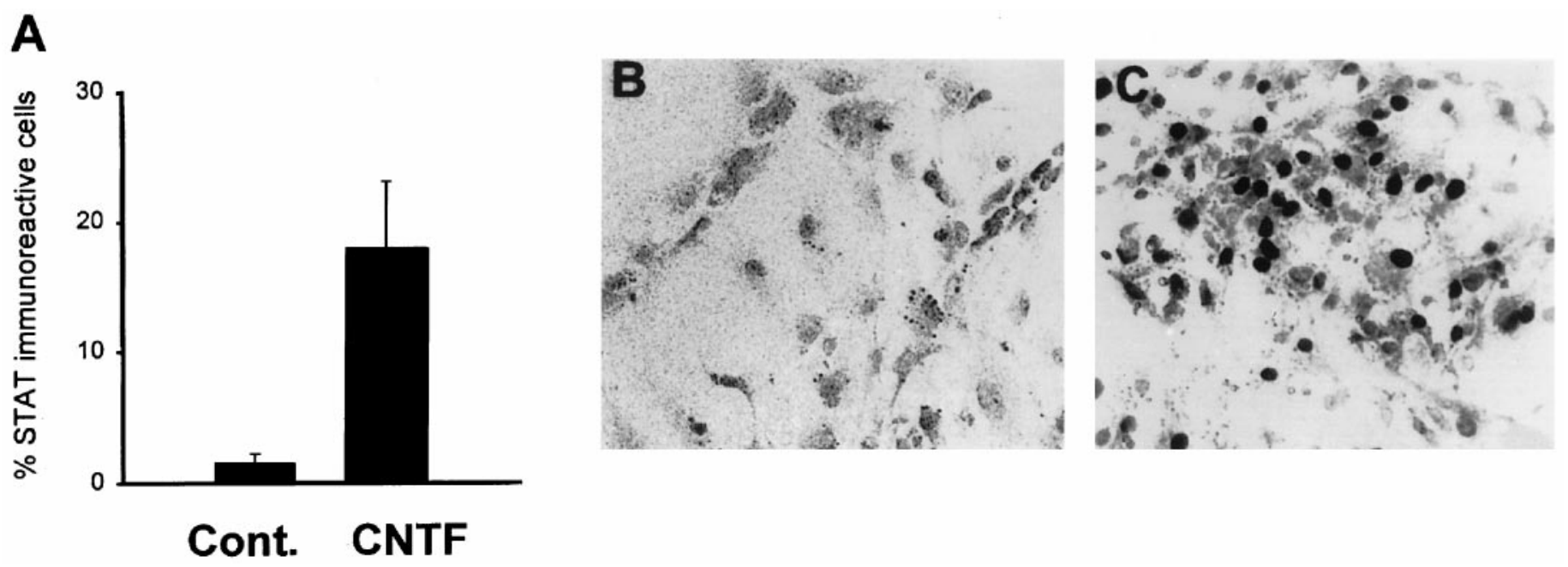

Figure 7. STAT-3 nuclear translocation in progenitor cells derived from cortical multipotent cells after gp130-associated cytokine applications. EGF-generated progenitor cell cultures were stimulated with growth factors $(30 \mathrm{~min})$ and fixed and processed for peroxidase immunocytochemistry using anti-STAT-3 antibodies. $A$, The percentage of progenitors that exhibit STAT-3 nuclear translocation after stimulation. $B$, $C$, Photomicrographs demonstrating that STAT-3 displays a cytoplasmic distribution in control conditions $(B)$ and predominant nuclear distribution in a subpopulation of progenitor cells after stimulation with $\mathrm{CNTF}(C)$. In $A$ each bar represents the mean \pm SEM of three independent observations. Similar results were obtained in four separate experiments.

lation of the cells exhibiting STAT-3 translocation also was immunoreactive for A2B5 $(29.8 \pm 2.2 \%)$.

\section{A subpopulation of cortical OL progenitor cells is responsive to CNTF}

To determine whether primary cortical OL progenitors also exhibit similar patterns of phosphorylation and nuclear translocation of STAT-3, we established primary cultures of OL progenitors from PN2 rat cortex and examined their cellular responsiveness to CNTF. The cellular composition of this OL progenitor culture system has been described previously; A2B5positive OL progenitors (Fig. $8 F$, day 0 ) gradually differentiate and generate differentiated OLs that express myelin proteins (Fig. 8F, days 4-7) (Cohen et al., 1996). Western blot analysis demonstrated that STAT-3 is initially expressed in developing cortical OL progenitors (A2B5- or O4-immunoreactive; Fig. $8 F$, days $0-1)$ and persists through advanced stages of OL differentiation (Fig. 8F, days 4-7). Double immunocytochemical analysis revealed that untreated O4-immunoreactive OL progenitors display a cytoplasmic distribution of STAT-3 (Fig. 8A,B). After brief (30 $\mathrm{min}$ ) application of CNTF, a significant subpopulation $(23.1 \pm 2.1 \%)$ of the O4-positive cells exhibited nuclear translo- cation of STAT-3 (Fig. 8C-E). To examine the time course and the specificity of CNTF-induced STAT-3 phosphorylation further, we grew cortical OL progenitors at high density (see Materials and Methods) and challenged them with CNTF. After 1, 5, 30, and $120 \mathrm{~min}$, progenitor cells were lysed and processed for Western blot analysis to detect the presence of activated (phosphorylated) STAT-3 (see Materials and Methods). CNTF induced rapid and transient phosphorylation of STAT-3 (Fig. 8G). Our cumulative observations demonstrate that CNTF may be a developmentally relevant ligand for a subpopulation of two distinct postnatal cortical OL progenitor populations, primary OL progenitor cells and those derived from cortical multipotent progenitors. Primary cortical OL progenitors exhibit responsiveness to CNTF but generate differentiated OLs by cell-intrinsic mechanisms. By contrast, OL maturation from OL progenitors derived from cortical multipotent progenitor cells requires environmental signals including CNTF.

\section{DISCUSSION}

Primary cortical OL progenitors can generate differentiated OLs via cell-autonomous mechanisms (Barres and Raff, 1994) without 

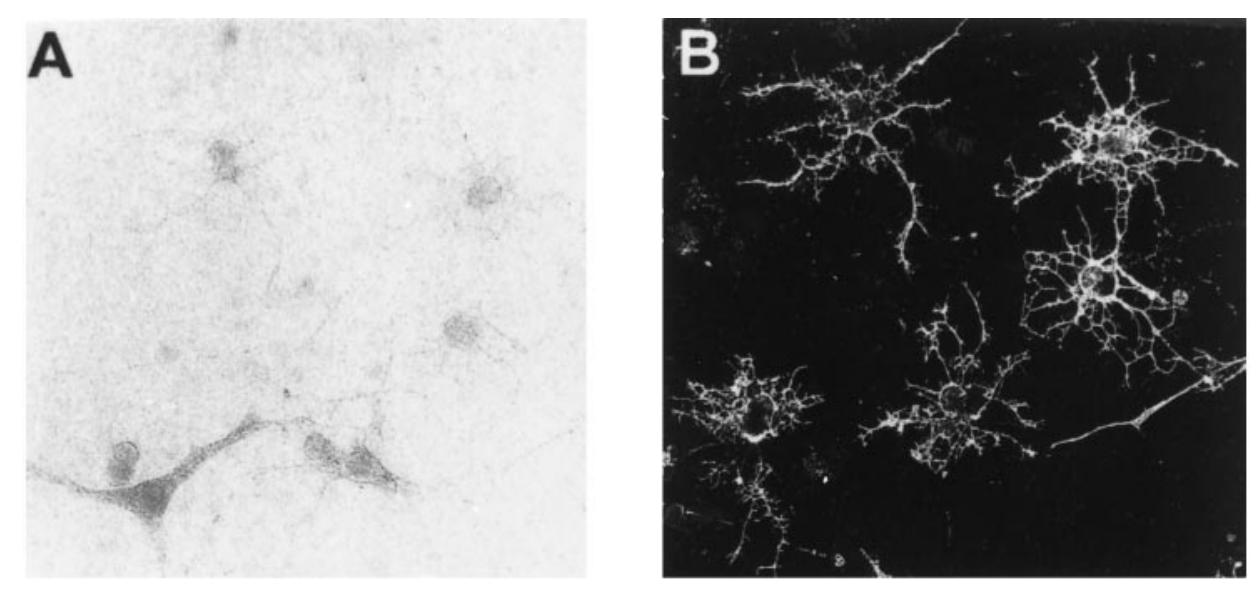

Figure 8. Expression, nuclear translocation, and phosphorylation of STAT-3 in primary developing cortical oligodendrocytes after gp130-associated cytokine applications. Primary OL progenitors $(\mathrm{O} 4-$ expressing cells) were isolated and stimulated with gp130 cytokines (see Materials and Methods). After stimulation (30 min), cells were initially stained with $\mathrm{O} 4 \mathrm{mAbs}$ and subsequently were fixed and processed for immunoperoxidase cytochemistry using anti-STAT-3 antibodies. $A-D$, Representative microscopic fields demonstrating STAT-3 immunoreactivity under light microscopy $(A, C)$ in O4-positive cells (FITC; $B, D)$. STAT-3 exhibited cytoplasmic distribution in control conditions $(A, B)$ and predominantly nuclear distribution in subpopulations of O4-positive progenitor cells after stimulation with CNTF $(C, D)$. E, The percentage of O4-positive progenitors that exhibit STAT-3 nuclear translocation in each experiment condition. Each bar represents the mean \pm SEM of three independent observations. Similar results were obtained in two separate experiments. $F$, Western blot analysis demonstrating the expression of STAT-3 during the oligodendrocyte progenitor stage (A2B5+; day 0$)$, the preoligodendrocyte stage $(\mathrm{O} 4+$; days $0-1)$, and the mature OL stage (MBP+; days 4-7). $G$, Levels of expression of phosphorylated STAT-3 (top) and total STAT-3 protein (bottom) before and after application of CNTF $(50 \mathrm{ng} / \mathrm{ml})$. Lane 1, Control; lanes 2-5, CNTF stimulation for 1, 5, 30,
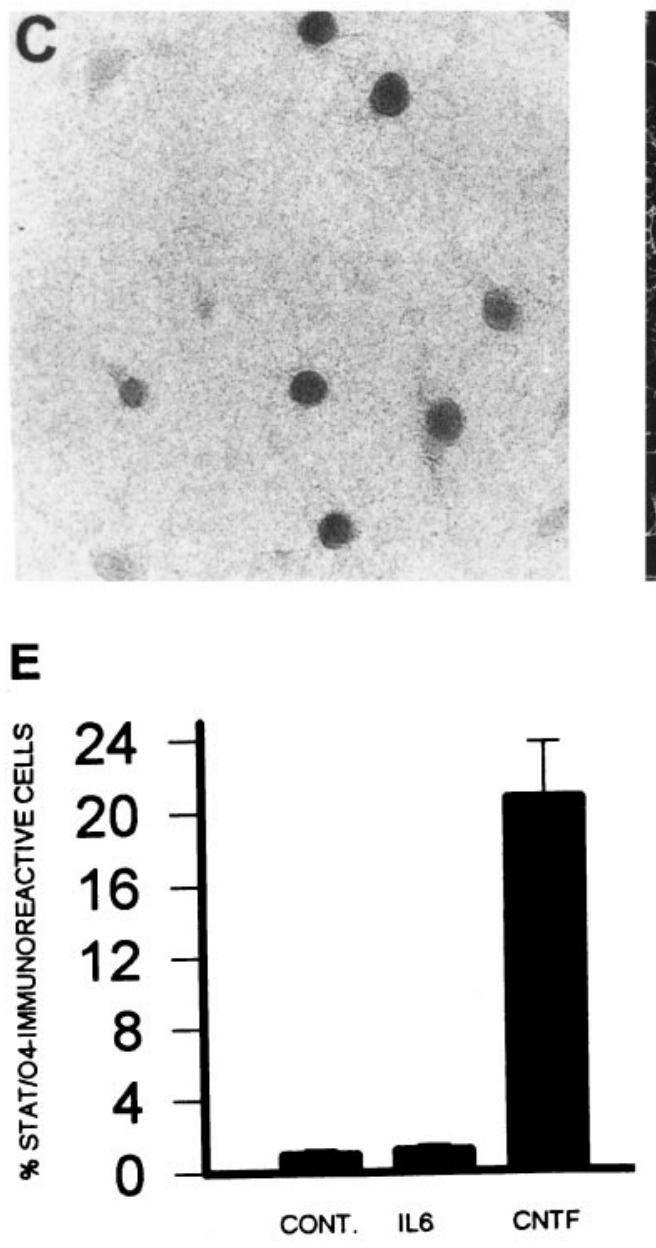

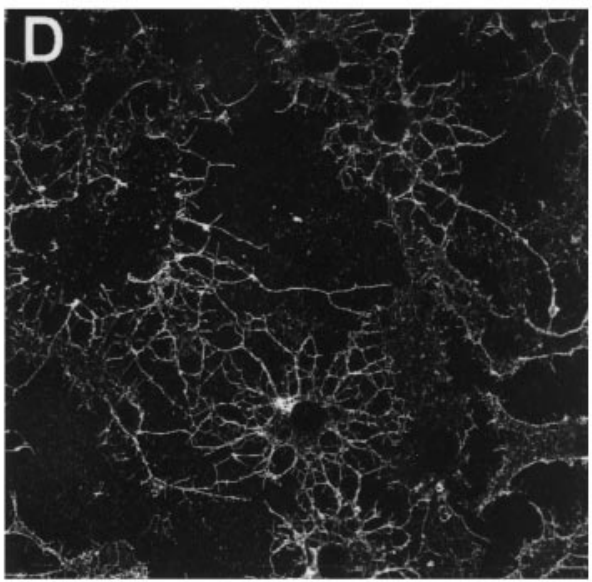

$\mathbf{F}$

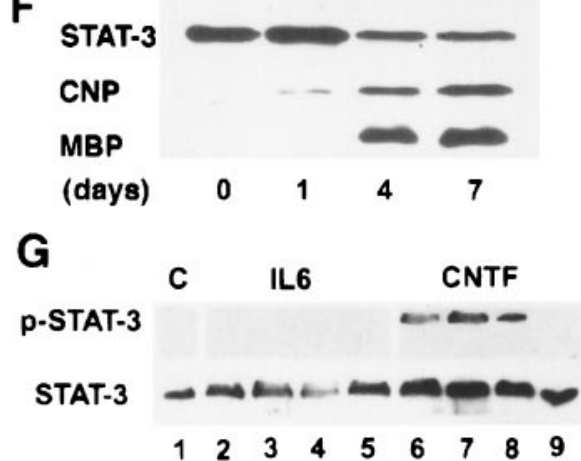
and $120 \mathrm{~min}$.

the requirement for exogenous signals (Fig. 2). In this study, by contrast, we have demonstrated that OL progenitors derived from cortical multipotent progenitor cells do not give rise to differentiated OLs without exogenous cues. However, treatment of these cells with CNTF supported the generation of differentiated OLs by acting directly on the O4-immunoreactive cells as demonstrated by phosphorylation and nuclear translocation of STAT-3. Thus, terminal OL maturation from cortical multipotent progenitors requires environmental signals including activation of gp130/LIF $\beta$ heterodimeric receptors.

\section{Generation of differentiated oligodendrocytes from early postnatal cortical EGF-responsive multipotent progenitors is dependent on environmental signals}

Recent studies have suggested that OL differentiation in vivo is dependent on exogenous cues present in the postnatal cerebral cortex (Levison et al., 1993; Levison and Goldman, 1997). We therefore examined whether the generation of differentiated OLs from OL progenitors present within clonal density cultures of cerebral cortical multipotent progenitors is governed by cell autonomous mechanisms (Raff et al., 1985; Barres and Raff, 1994) 
or is dependent on environmental signals (Levison et al., 1993; Zhang and Miller, 1995). Propagation of multipotent progenitor cultures with or without bFGF, NT3, and PDGF at clonal density supported the generation of OL progenitors but not the elaboration of differentiated OLs despite robust cumulative survival $(>90 \%)$ over prolonged periods in vitro (9 d; Table 1$)$. Generation of oligodendrocytes from optic nerve-derived OL progenitors cultured in the presence of mitogens (PDGF) is dependent on the presence of thyroid hormone or hydrocortisone (Barres et al., 1994). However both factors were present in the culture media used in these studies (see Materials and Methods), excluding the possibility that the absence of these molecules prevented the generation of oligodendrocytes. These observations suggest that the generation of differentiated OLs from cortical multipotent cells is dependent on environmental cues.

\section{CNTF and additional environmental cues promote the generation of differentiated oligodendrocytes from OL progeny of multipotent cells}

Treatment of multipotent progenitor cultures with CNTF resulted in the generation of differentiated OLs. The effects of CNTF could reflect action on multipotent cells by either a selective or instructive mechanism (see Morrison et al., 1997) or alternatively could reflect actions on cells committed previously to the OL lineage (e.g., O4-immunoreactive cells) (see Morrison et al., 1997). However, application of CNTF did not alter indices of proliferation (BrdU) or cumulative survival (MTT assay), indicating that the factor did not act by selective mechanisms (Table 1). In addition, there was no change in the proportion of neuronal, astroglial, or oligodendroglial progenitor species (Fig. 3), indicating that CNTF did not act directly on the multipotent cells to support the elaboration of OL lineage species at the expense of alternate lineages (instructive mechanisms). This suggests that the cytokine promoted OL differentiation by acting on cells committed previously to the OL lineage. In fact, CNTF treatment of the multipotent progenitor cultures resulted in STAT-3 nuclear translocation within the O4-immunoreactive subpopulations, indicating a direct effect on these cells. In addition, the percentage of differentiated OLs generated after CNTF application (Fig. $1 B$ ) was similar to the percentage of cells exhibiting STAT-3 (Fig. 7A). Our observations are consistent with those of Mayer et al. (1994), indicating maturational effects of CNTF on cultures of primary OL progenitors. However, the primary OL progenitor cultures used by Mayer et al. (1994) supported the generation of differentiated OLs even in the absence of exogenous signals such as CNTF, raising questions about whether CNTF was necessary for cellular differentiation.

Although clonal density cultures of EGF-responsive progenitors required exposure to $\mathrm{CNTF}$ for the generation of differentiated O1-immunoreactive OLs (Fig. $1 B$ ), higher density cultures spontaneously give rise to mature OLs, including myelin proteinexpressing lineage species (Fig. 4B). These observations suggested that endogenous signals present within higher density progenitor cultures could promote the elaboration of mature OLs from cortical multipotent cells. Conditioned media from moderate density cortical progenitor cultures could not reproduce the CNTF-mediated elaboration of differentiated OLs observed in clonal density progenitor cultures (Fig. 5B). This observation suggested that environmental signals other than CNTF were responsible for the density-dependent effects on OL differentiation. In addition, blocking antibodies to LIF $\beta$ receptor but not to gp130 could dramatically attenuate the CNTF-mediated OL- differentiating effect observed in clonal density progenitor cultures (Fig. 5B). Thus, the OL maturational effects of CNTF seem to be preferentially mediated by LIF $\beta$ receptor activation. When applied individually or as reagent coapplications to moderate density cortical progenitor cultures (Fig. $5 A$ ), LIF $\beta$ receptor- and gp130-blocking antibodies failed to alter the basal profile of elaboration of differentiated OLs. These cumulative findings suggest that the density-dependent potentiation of OL lineage maturation from cortical multipotent progenitors is mediated by environmental cues other than those that signal through gp130 and LIF $\beta$ receptors. These latter signals include CNTF, LIF, interleukin 6 and 11, and a component of oncostatin-Mresponsive pathways (Stahl and Yancopoulos, 1994; Taga and Kishimoto, 1997).

\section{The effects of CNTF on the generation of OLs from EGF-responsive multipotent progenitor cells: relevance for perinatal gliogenesis but not embryonic neurogenesis}

Recent studies performed on primary embryonic cortical and hippocampal progenitor cells grown on substrate in the presence of bFGF and CNTF have suggested that CNTF acts as an instructive signal for astroglial lineage commitment (Johe et al., 1996; Bonni et al., 1997). However, application of CNTF to EGF-generated multipotent progenitors does not induce astroglial differentiation but rather increases the number of MBPimmunoreactive OLs (Reynolds et al., 1993). Furthermore, our clonal density analysis has demonstrated that CNTF does not act as an instructive signal for oligodendroglial lineage commitment from EGF-responsive cells but rather acts to promote cellular maturation of OL progenitors derived from cortical EGFresponsive multipotent cells (Table 1; Fig. 1C). Thus, the biological actions of CNTF may be context-dependent such that the cytokine exerts different cellular actions on bFGF-responsive and EGF-responsive progenitor cells. There is now increasing evidence that EGF-responsive multipotent progenitor cells play an essential role during perinatal gliogenesis but not during embryonic neurogenesis (Lazar and Blum, 1992; Ferrer et al., 1995; Threadgil et al., 1995; Burrows et al., 1997), whereas bFGFresponsive cells may play a more important role during earlier embryonic cortical development (Kilpatrick and Bartlett, 1995; Qian et al., 1997). Maximal expression of CNTF occurs within the postnatal cerebral cortex (Stockli et al., 1991), suggesting the relevance of this ligand for postnatal oligodendrogliogenesis.

It is currently unclear whether the EGF-responsive cortical and subventricular zone-derived multipotent progenitors represent independent lineages or two distinct stages of the same lineage. PSA-NCAM mediates cell-cell interactions and has been implicated as a mediator of cellular plasticity (Rutishauser, 1996; Rutishauser and Landmesser, 1996). Thus, although PSA-NCAM may mediate migration of progenitor species from the subventricular zone to the cerebral cortex, this developmental molecule may also represent an independent mechanism for regulating the environmental plasticity of EGF-responsive cortical multipotent progenitors. Therefore, the cortical multipotent progenitors may be derived from several developmental sources and exhibit distinct cellular mechanisms: continuous migration during early postnatal cerebral cortical development, earlier embryonic stage migration to the developing cortex, and persistence as relatively quiescent or self-renewing populations or as intrinsic elements of the postnatal cerebral cortex. 


\section{Cytokines that signal through gp130/LIB $\beta$ receptors: implications for oligodendroglial development in vivo}

Although the optic nerves of homozygous CNTF null mice contain reduced numbers of proliferating OL progenitors, myelination in the nerves is normal (Barres et al., 1996). The authors concluded that CNTF supports the proliferation of OL progenitors but does not promote OL differentiation. However, this study did not include immunocytochemical analysis using markers of OL progenitors and mature oligodendrocytes. Thus, it did not directly address the issue of whether deficiency of CNTF in the optic nerve actually retards the generation of differentiated OLs. In addition, optic nerve-derived OL progenitors may exhibit cellular properties distinct from those of cortically derived OL progenitor species (Miller, 1996). Furthermore, the general developmental defects exhibited by $\mathrm{CNTF}-/-$ mice are much less severe than are those exhibited by $\mathrm{CNTF} \alpha$ receptor $-/-$ mice, suggesting that an additional CNTF-like protein(s) may contribute to gp130/LIF $\beta$ receptor heterodimeric signaling during development in vivo (Stahl and Yancopoulos, 1994; DeChiara et al., 1995). Moreover, recent analysis of mice lacking the LIF $\beta$ receptor subunit has shown that these animals display many more widespread developmental deficits than does the CNTF $\alpha$ receptor knock-out mouse, including abnormal gliogenesis (DeChiara et al., 1995; Ware et al., 1995). This genetic evidence strongly suggests that CNTF and additional gp130-related cytokines, such as oncostatin M (OSM) or cardiotrophin-1, may contribute to LIF $\beta$ receptor-mediated signaling during gliogenesis in vivo. The effects of OSM on developing forebrain oligodendrocytes are similar to those of CNTF (Reynolds et al., 1993; Gard et al., 1995a; Marmur and Mehler, unpublished observations). Furthermore, cortical astrocytes secrete a protein with LIF-like activity that supports the survival of a greater number of cortical OL progenitors than either LIF or CNTF supports (Gard et al., 1995b). Because we have demonstrated that selective activation of gp130/LIF $\beta$ heterodimeric receptors enhances the generation of differentiated OLs from cortical multipotent progenitor cells, the detailed characterization of additional CNTF- or LIF-like protein(s) will facilitate our understanding of how differentiated OLs are generated during cortical gliogenesis in vivo.

\section{REFERENCES}

Almazan G, Afar DEH, Bell JC (1993) Phosphorylation and disruption of intermediate filament proteins in oligodendrocyte precursor cultures treated with calyculin A. J Neurosci Res 36:163-172.

Altman J (1966) Proliferation and migration of undifferentiated precursor cells in the rat during postnatal gliogenesis. Exp Neurol 16:263-278.

Armstrong RC, Kim JG, Hudson LD (1995) Expression of myelin transcription factor (MyT 1), a "zinc-finger" DNA-binding protein, in developing oligodendrocytes. Glia 14:303-321.

Barres BA, Raff MC (1994) Control of oligodendrocyte numbers in the rat optic nerve. Neuron 12:935-942.

Barres BA, Lazar MA, Raff MC (1994) A novel role for thyroid hormone, glucocorticoids and retinoic acid in timing oligodendrocyte development. Development 120:1097-1108.

Barres BA, Burne JF, Holtman B, Thoenen H, Sendtner M, Raff MC (1996) Ciliary neurotrophic factor enhances the rate of oligodendrocyte generation. Mol Cell Neurosci 8:146-156.

Bonni A, Yi S, Nadal-Vicens M, Bhatt A, Frank DA, Rozovsky I, Stahl N, Yancopoulos GD, Greenberg ME (1997) Regulation of gliogenesis in the central nervous system by the JAK-STAT signaling pathway. Science 278:477-483.

Bunge MB, Bunge RP, Pappas GD (1962) Electron microscopic demonstration of connections between glia and myelin sheaths in the developing mammalian central nervous system. J Cell Biol 12:448-453.

Burrows RC, Wancio D, Levitt P, Lillien L (1997) Response diversity and timing of progenitor cell maturation are regulated by developmen- tal changes in EGF receptor expression in the cortex. Neuron 19:251-267.

Cohen RI, Marmur R, Norton WT, Mehler MF, Kessler JA (1996) Nerve growth factor and neurotrophin-3 differentially regulate the proliferation and the survival of developing rat brain oligodendrocytes. J Neurosci 16:6433-6442.

DeChiara TM, Vejsada R, Poueymirou WT, Acheson A, Suri C, Conover JC, Friedman B, McClain J, Pan L, Stahl N, Ip NY, Kato A, Yancopoulos GD (1995) Mice lacking the CNTF receptor unlike mouse lack CNTF exhibit profound motor neuron deficits at birth. Cell 83:313-322.

Del Rio Hortega P (1928) Tercera aportacion al conocimiento morphologico e interpretacion functional de la oligodendroglia. Mem R Soc Esp Hist Nat 14:5-122.

Eisenbarth GS, Walsh FS, Nirenberg M (1979) Monoclonal antibody to a plasma membrane antigen of neurons. Proc Natl Acad Sci USA 76:4913-4917.

Ferrer I, Blanco M, Carulla R, Alcantara S, Olive M, Planas A (1995) Transforming growth factor $\alpha$ immunoreactivity in the developing and adult brain. Neuroscience 66:189-199.

Gard AL, Burrell MR, Pfeiffer SE, Rudge JS, Williams WC (1995a) Astroglial control of oligodendrocyte survival is mediated by PDGF and leukemia inhibitory factor-like protein. Development 121:2187-2197.

Gard AL, Williams II WC, Burrell MR (1995b) Oligodendroblasts distinguished from $\mathrm{O}-2 \mathrm{~A}$ glial progenitors by surface phenotype $(\mathrm{O} 4+\mathrm{Gal}$ $\mathrm{C}-$ ) and response to cytokines using signal transducer LIFR beta. Dev Biol 167:596-608.

Gross RE, Mehler MF, Mabie PC, Zang Z, Santschi L, Kessler JA (1996) Bone morphogenetic proteins promote astroglial lineage commitment by mammalian subventricular zone progenitor cells. Neuron 17:595-606.

Groves AK, Barnet SC, Richardson WD (1993) Repair of demyelinated lesions by transplantation of purified O-2A progenitor cells. Nature 362:453-455.

Hammang JP, Archer DR, Duncan ID (1997) Myelination following transplantation of EGF-responsive neural stem cells into a myelindeficient environment. Exp Neurol 147:84-95.

Hardy RJ, Reynolds R (1991) Proliferation and differentiation potential of rat forebrain oligodendrocyte progenitors both in vitro and in vivo. Development 111:1061-1080.

Ibarrola N, Mayer-Proschel M, Rodriguez-Pena A, Noble M (1996) Evidence for the existence of at least two timing mechanisms that contribute to oligodendrocyte generation in vitro. Dev Biol 180:1-21.

Johe KK, Hazel TG, Muller T, Dugich-Djordjevic MM, McKay RD (1996) Single factors direct the differentiation of stem cells from the fetal and the adult central nervous system. Genes Dev 10:3129-3140.

Kilpatrick TJ, Bartlett PF (1995) Cloned multipotential precursors from the mouse cerebrum require FGF-2, whereas glial restricted progenitors are stimulated either with FGF-2 or EGF. J Neurosci 15:3653-3661.

Lazar LM, Blum M (1992) Regional distribution and developmental expression of epidermal growth factor and transforming growth factor $\alpha$-mRNA in mouse brain by quantitative nuclease protection assay. J Neurosci 12:1688-1697.

LeVine SM, Goldman JE (1988a) Embryonic divergence of oligodendrocyte and astrocyte lineages in developing rat cerebrum. J Neurosci 8:3992-4006.

LeVine SM, Goldman JE (1988b) Spatial and temporal patterns of oligodendrocyte differentiation in rat cerebrum and cerebellum. J Comp Neurol 277:441-455.

Levison SW, Goldman JE (1997) Multipotent and lineage restricted precursors coexist in the mammalian perinatal subventricular zone. J Neurosci Res 48:83-94.

Levison SW, Chuang C, Abramson BJ, Goldman JE (1993) The migration patterns and developmental fates of glial precursors in the rat subventricular zone are temporally regulated. Development 119:611-622.

Mabie PC, Mehler MF, Marmur R, Papavasiliou A, Song Q, Kessler JA (1997) Bone morphogenetic proteins induce astroglial differentiation of oligodendroglial-astroglial progenitor cells. J Neurosci 17: 4112-4120.

Manthorpe MR, Fagnani SD, Skaper S, Varon S (1986) An automated colorimetric microassay for neurotrophic factors. Dev Brain Res 25:191-198. 
Marmur R, Mabie PC, Gokhan S, Song Q, Kessler JA, Mehler MF (1998) Isolation and developmental characterization of cerebral cortical multipotent progenitors. Dev Biol, in press.

Mayer M, Bhakko K, Noble M (1994) Ciliary neurotrophic factor and leukemia inhibitory factor promote the generation, maturation and survival of O-2A progenitor cells in vitro. Development 120:143-153.

McCarthy KD, deVellis J (1980) Preparation of separate astroglial and oligodendroglial cell cultures from rat cerebral tissue. J Cell Biol 85:890-902.

Miller RH (1996) Oligodendrocyte origins. Trends Neurosci 19:92-96.

Morrison SJ, Shah NM, Anderson DJ (1997) Regulatory mechanisms of stem cell. Cell 88:187-197.

Paterson JA, Privat A, Ling EA, Leblond CP (1973) Investigation of glial cells in biology in semithin sections. 3. Transformation of subependymal cells into glial cells, as shown by radioautography after ${ }^{3} \mathrm{H}$ thymidine injection into the lateral ventricle of the brain of young rats. J Comp Neurol 149:83-102.

Pfeiffer SE, Warrington AE, Bansal R (1993) Oligodendrocyte and its many cellular processes. Trends Neurosci 3:191-198.

Qian X, Davis AA, Golderie SK, Temple S (1997) FGF-2 concentration regulates the generation of neurons and glia from multipotent cortical stem cells. Neuron 18:81-93.

Raff MC, Abney EA, Fok-Seang J (1985) Reconstitution of the developmental clock in vitro: a critical role for astrocytes in the timing of oligodendrocyte differentiation. Cell 42:61-69.

Reid CB, Walsh CA (1996) Early development of the cerebral cortex. Prog Brain Res 108:17-30.

Reynolds BA, Weiss S (1992) Generation of neurons and astrocytes from isolated cells of the adult mammalian central nervous system. Science 255:1707-1710.

Reynolds BA, Tetzlaff W, Weiss SA (1992) Multipotent EGFresponsive striatal embryonic progenitor cell produces neurons and astrocytes. J Neurosci 12:4565-4574.

Reynolds BA, Hammang JP, Baetge EE, Weiss S (1993) CNTF, LIF and oncostatin $\mathrm{M}$ increase the number of oligodendrocytes in cultures of EGF-generated CNS progenitor cells. Soc Neurosci Abstr 19:870.

Rutishauser U (1996) Polysialic acid and the regulation of cell interactions. Curr Opin Cell Biol 8:679-684.

Rutishauser U, Landmesser L (1996) Polysialic acid in the vertebrate nervous system: a promoter of plasticity in cell-cell interactions. Trends Neurosci 19:422-427.

Schobitz B, Voorhuis DA, DeKloet ER (1992) Localization of interleu- kin 6 mRNA and interleukin 6 receptor RNA in rat brain. Neurosci Lett 136:189-192.

Schobitz B, de Kloet ER, Sutanto W, Holsboer F (1993) Cellular localization of interleukin 6 mRNA and interleukin 6 receptor mRNA in rat brain. Eur J Neurosci 5:1426-1435.

Sommer I, Schachner M (1981) Monoclonal antibodies (O1 to O4) to oligodendrocyte cell surfaces: an immunocytological study in the central nervous system. Dev Biol 83:311-327.

Stahl N, Yancopoulos GD (1994) The tripartite CNTF receptor complex: activation and signaling involves components shared with other cytokines. J Neurobiol 25:1454-1466.

Stockli KA, Lillien LE, Naher-Noe M, Breitfeld G, Hughes RA, Raff MC, Thoenen H, Sendtner M (1991) Regional distribution, developmental changes, and cellular localization of CNTF-mRNA and protein in the rat brain. J Cell Biol 115:447-459.

Taga T, Kishimoto T (1997) Gp130 and the interleukin-6 family of cytokines. Annu Rev Immunol 15:797-819.

Temple S, Qian X (1996) Vertebrate neural progenitor cells: subtypes and regulation. Curr Opin Neurobiol 6:11-17.

Threadgil DW, Dlugosz AA, Hansen AA, Tennenboum T, Lichti U, Yee D, LaMatina C, Mourtom T, Herrup G, Harris RC, Barnard JA, Yuspa SH, Coffey RJ, Magnuson T (1995) Targeted disruption of mouse EGF receptor: effect of genetic background on mutant phenotype. Science 269:230-234.

Ware CB, Horowitz MC, Renshow BR, Hunt JS, Liggit D, Koblar SA, Gliniak BC, McKenne HJ, Papayannopoulo T, Thoma B, Cheng L, Donovan PJ, Peschon JJ, Bartlett PE, Willis CR, Wright BD, Carpenter M (1995) Targeted disruption of the low affinity leukemia inhibitory factor receptor gene causes placental, skeletal, neural and metabolic defects and results in prenatal death. Development 121:1283-1299.

Weiss S, Reynolds BA, Vescovi A, Morshead C, Craig CG, Van der Kooy $\mathrm{D}$ (1996) Is there a neural stem cell in the mammalian forebrain? Trends Neurosci 19:387-393.

Zhang H, Miller RH (1995) Asynchronous differentiation of clonally related spinal cord oligodendrocytes. Mol Cell Neurosci 6:16-31.

Zhong Z, Zilong W, Darnell JE (1994a) STAT 3: a STAT family member activated by tyrosine phosphorylation in response to epidermal growth factor and interleukin 6. Science 264:95-98.

Zhong Z, Wen Z, Darnell JE (1994b) STAT 3 and STAT 4: members of the family of signal transducers and activators of transcription. Proc Natl Acad Sci USA 91:4806-4810. 